\title{
Effect of antivascular endothelial growth factor treatment on the intratumoral uptake of CPT-I।
}

\author{
H Wildiers*,', G Guetens', G De Boeck', E Verbeken², B Landuyt', W Landuyt ${ }^{3}$, EA de Bruijn' \\ and AT van Oosterom' \\ 'Laboratory of Experimental Oncology (LEO), University Hospital Gasthuisberg, Herestraat 49, B-3000 Leuven, Belgium; ${ }^{2}$ Department of \\ Histopathology, University Hospital Gasthuisberg, Herestraat 49, B-3000 Leuven, Belgium; ' ${ }^{2}$ Laboratory of Experimental Radiobiology/LEO; \\ University Hospital Gasthuisberg, Herestraat 49, B-3000 Leuven, Belgium
}

\begin{abstract}
Promising preclinical activity with agents blocking the function of vascular endothelial growth factor (VEGF) has been observed in various cancer types, especially with combination therapy. However, these drugs decrease microvessel density, and it is not known whether this reduced vessel density (VD) results in decreased delivery of concomitantly administered classical anticancer drugs. We designed an in vivo study to investigate the relation between VEGF-blocking therapy, tumoral blood vessels, and intratumoral uptake of anticancer drugs. Nude NMRI mice bearing colon adenocarcinoma (HT29) were treated with the anti-VEGFmAb A4.6.I or placebo. After I week, CPT-I I was administered I h prior to killing the animals. In A4.6.I treated tumours, there was a significant decrease in VD, more pronounced with potentially functional large vessels than endothelial cords. Interestingly, a trend to increased intratumoral CPT-I I concentration was observed $(P=0.09)$. In parallel, we measured an increase in tumour perfusion, as estimated by high-performance liquid chromatography determination of intratumoural Hoechst 33342 concentration. In the growth delay study, CPT-I I was at least equally effective with or without pretreatment with A4.6.I. These data suggest that tumour vascular function and tumour uptake of anticancer drugs improve with VEGF-blocking therapy, and indicate the relevance for further investigations. British Journal of Cancer (2003) 88, 1979 - 1986. doi:I0.I038/sj.bjc.660 I005 www.bjcancer.com
\end{abstract} (c) 2003 Cancer Research UK

Keywords: anti-VEGF mAb; CPT-II; tumour delivery; Hoechst 33342; perfusion

Antiangiogenic therapy (AAT) inhibits new blood vessel formation and decreases vessel density (VD) and tumour growth in several tumour models (Kim et al, 1993; Borgstrom et al, 1998; Kamiya et al, 1999; Lee et al, 2000; Soh et al, 2000; Beecken et al, 2001; Shaheen et al, 2001). As a consequence, one would expect that tumour blood flow and tumour oxygenation also decrease during AAT. However, counterintuitive results have seemingly been demonstrated in several settings. Hypoxia is unchanged or reduced with squalamine (Teicher et al, 1998), the combination of TNP-470 and minocycline (Teicher et al, 1995b), and with the anti-VEGF $\mathrm{mAb}$ A4.6.1 (Lee et al, 2000). In addition, interstitial fluid pressure (IFP) is significantly reduced by the latter agent in the LS174T colon carcinoma model (Lee et al, 2000). Conclusive data concerning alterations in overall tumour perfusion after AAT are lacking. One study with interleukin-12 as an antivascular agent suggested decreased overall tumour perfusion (Gee et al, 2001). An interesting new concept that AAT may normalise the established tumour vasculature apart from inhibiting new vessel formation, has emerged (Jain, 2001). This 'normalisation' could lead to better tumour perfusion, oxygenation, and also to better delivery and efficacy of therapeutic agents. Several studies have shown that AAT potentiates the efficacy of standard anticancer drugs with enhanced delay of tumour growth (Teicher et al, 1992, 1994;

\footnotetext{
*Correspondence: Dr H Wildiers;

E-mail: hans.wildiers@uz.kuleuven.ac.be

Received 19 December 2002; revised 10 March 2003; accepted 7 April 2003
}

Sweeney et al, 2001), stimulating interest in combining these two treatment modalities. Also, low-dose (metronomic) regimens of standard chemotherapy can have clear preclinical activity without significant toxicity, and when combined with AAT may lead to full and sustained regressions (Browder et al, 2000; Klement et al, 2000; Man et al, 2002). One study has suggested that pretreatment with the antiangiogenic drug TNP-470 and minocycline results in increased intratumoral drug levels of platinum (Teicher et al, 1995a). TNP-470 is a semisynthetic derivative of fumagillin, a naturally occurring direct inhibitor of endothelial proliferation (Ingber et al, 1990). Unfortunately, phase I studies with TNP-470 showed dose-limiting neurotoxicity with only minor tumour response (Bhargava et al, 1999; Stadler et al, 1999; Logothetis et al, 2001), and interest in using this drug clinically has diminished. Antiangiogenic therapy increases tumour radiation response, further supporting the new concept of 'normalising tumour vasculature' (Gorski et al, 1999; Lee et al, 2000; Kozin et al, 2001). In these studies, AAT decreases rather than increases hypoxia, explaining at least in part the increased radiosensitivity of the tumour cells.

Vascular endothelial growth factor (VEGF) is a key growth factor in the angiogenic process, and has a role in endothelial cell migration, proliferation, vascular permeability, and endothelial cell apoptosis. Inhibition of VEGF function by tyrosine kinase inhibitors, or monoclonal antibodies against VEGF or one of its receptors, has a significant antitumour effect. The monoclonal VEGF antibody A4.6.1 significantly decreases VD, tumour growth, and IFP, in several tumour models including colorectal cancer (Kim et al, 1993; Borgstrom et al, 1998; Lee et al, 2000; Rowe et al, 
2000). This monoclonal antibody with the product name 'Bevacizumab' has also shown promising clinical activity without major toxicity in patients with metastatic renal cancer (Yang et al, 2002), and phase III clinical trials are ongoing. An increased tumour radiation response has been observed with A4.6.1 (Lee et al, 2000), but there are no data available regarding the effect of the antibody on the tumour availability of anticancer drugs. In this study, we have examined the effect of A4.6.1 on the intratumoral availability of the cytotoxic CPT-11 in a colorectal cancer model. Vascular function was evaluated after treatment using the perfusion marker Hoechst 33342 (H33342). CPT-11 is a topoisomerase I inhibitor that is increasingly used in colon cancer, with a biological half-life of about $1 \mathrm{~h}$ in mice (Kaneda et al, 1990). A prodrug, it is converted by decarboxylation in the liver into the active metabolite SN-38, which is much more cytotoxic than the parent compound. According to the paradigm of normalising tumour vasculature with $\mathrm{AAT}$, it is possible that delivery of CPT-11 is increased rather than decreased when given with VEGF-blocking agents.

\section{MATERIALS AND METHODS}

\section{Materials}

The humanised murine antihuman VEGF mAb A. 4.6.1. was kindly provided by Genentech (South San Francisco, CA, USA). CPT-11 was a gift from Aventis Pharma Belgium (Brussels, Belgium). CPT11 solution was freshly prepared in $0.9 \%$ saline at a concentration of $10 \mu \mathrm{g} \mu \mathrm{l}^{-1}$.

\section{Tumour cell lines}

The HT29 human colon cancer cell line was obtained from the American Type Culture Collection (Manassas, VA, USA), and cultured under $5 \% \mathrm{CO}_{2}$ in minimal essential medium (MEM) supplemented with $10 \%$ foetal bovine serum (FBS), $2 \mathrm{U} \mathrm{ml}^{-1}$ penicillin and streptomycin, $1 \mathrm{~mm}$ sodium pyruvate, $2 \mathrm{mM} \mathrm{L}$ glutamine, and nonessential amino acids at $37 \%$.

\section{Tumour xenografts in nude mice and drug administration}

Athymic male NMRI nude (nu/nu) mice, 6-8 weeks old, were used. They were fed a diet of animal chow and water ad libitum throughout the experiment. HT29 cells $\left(1 \times 10^{6}\right.$ cells in $100 \mu \mathrm{l}$ phosphate-buffered saline (PBS) were injected subcutaneously in the right and left flank of the animals. Tumour growth was assessed every 2-3 days. Three orthogonal diameters were measured with vernier callipers, and used to calculate the volume of the tumour using the formula $\mathrm{a} \times \mathrm{b} \times \mathrm{c} \times \pi / 6$ (Tomayko and Reynolds, 1989). When unilateral or bilateral tumours reached a volume of $200-300 \mathrm{~mm}^{3}$, the mice were randomised into two groups for the first part of the study, examining the intratumoral CPT-11 concentration (20 tumours per group), and into four groups for the second part of the study, examining the tumour growth delay (10 tumours per group). A measure of $200 \mu \mathrm{g}$ A4.6.1, diluted in saline, was administered intraperitoneally to each mouse (day 0 ). The same dose was given on day 4 . Control animals were injected with saline. A single injection of $100 \mathrm{mg} \mathrm{kg}^{-1} \mathrm{CPT}-11$ was administered intraperitoneally on day 7 . This dose produces a growth delay in our tumour model (data not shown), and is known to be the $\mathrm{LD}_{0}$ in mice (Lavelle et al, 1996). Control animals were injected with saline. Body weight, tumour volume, and time between subcutaneous cell inoculation and randomisation were not different in the various groups. The time between subcutaneous cell inoculation and randomisation was between 18 and 25 days. The mean was 23.6 days (treatment group) and 23.7 days (control group) for the first part, and between 20.1 and 21.2 days for the four groups in the second part. In the second part measuring tumour growth delay, mice were sacrificed when the largest tumour exceeded $1000 \mathrm{~mm}^{3}$. All the animal studies are in agreement with the Guidelines for the Welfare of Animals in Experimental Neoplasia (United Kingdom Co-ordinating Committee on Cancer Research (UKCCCR) 1998), and approved by the Animal Ethics Committee of the Catholic University Leuven.

\section{Tissue and blood sample preparation in the first part of the study}

The mice were killed at day 7 by ether inhalation one hour after the CPT-11 injection. A $500 \mu$ l blood sample was taken through an intracardiac puncture and collected in an EDTA tube, and the tumours were resected. Each tumour was halved, and one half was frozen slowly in methylbutane for microscopic evaluation. The other half was snap frozen in liquid nitrogen for the later measurement of tumour CPT-11 concentrations. The blood was centrifuged at $1500 \mathrm{~g}$ for $10 \mathrm{~min}$ in a swing-out rotor, and $100 \mu \mathrm{l}$ supernatant plasma was removed and used to measure plasma concentrations of CPT-11 and SN-38.

\section{Histological analysis}

Histological sections were stained for CD34 and CD105 with Biotin conjugated CD34 and CD105 antibody (BD Biosciences), at a dilution of $1: 40$, avidin-biotin complex, and diaminobenzidine as chromogen. Vessel density was counted on CD34 and CD105 immunostained slides, according to conventional stereological methods using an unbiased Gundersen counting frame (Gundersen, 1978). Briefly, 10-20 quadrats per tumour were assessed, selected via a stratified random sampling procedure at a magnification of $\times 200$, with the aim of counting at least 50 vessels per tumour (Wildiers et al, 2002). The image was unfocused while moving from one quadrat to another to avoid any bias in vessel counting. Counting was performed in one section through the largest diameter of the tumour. Vessels were separated into endothelial cords, where no lumen or a lumen smaller than $7 \mu \mathrm{m}$ (the size of an erythrocyte) was observed, and into large vessels (lumen $\geqslant 7 \mu \mathrm{m}$ ). In the large vessel group, the shortest luminal diameter was measured and noted. The proportion of tumour necrosis, expressed as a percentage, was estimated at a magnification of $\times 40$. All measurements were performed by two independent observers, with interobserver variability less than $10 \%$, and all data were pooled for further analysis. Total VD, endothelial cord VD, and large-vessel VD were calculated.

\section{Determination of vascular function using the perfusion marker $\mathrm{H} 33342$}

The use of a fluorescent dye, H33342, to visualise and quantify tumour functional vasculature when frozen sections are viewed under ultraviolet light has been described (Smith et al, 1988; Quinn et al, 1992). $\mathrm{H} 33342$ is frequently used as a perfusion marker in preclinical research, where the vessels with surrounding stained cells are usually counted microscopically (Thomas et al, 1996; Bernsen et al, 1999; Bussink et al, 2000; Ljungkvist et al, 2002). Although this analysis does not directly quantify the number of perfused vessels, it provides an estimate of the relative degree of perfused tumour vasculature. The results of this technique correlated with tumour blood flow measurement using doppler ultrasound in melanoma xenograft tumours (Goertz et al, 2002). Hoechst 33342 was freshly prepared in $1 \mathrm{ml}$ physiological saline per $100 \mathrm{~g}$ body weight, and administered at $40 \mathrm{mg} \mathrm{kg}^{-1}$ intravenously via the tail vein. The tumours were removed $1 \mathrm{~min}$ after dosing. Rather than count the number of H33342-labelled cells microscopically, we decided to determine the global H33342 uptake in the tumour using HPLC. The same HPLC procedure as for the CPT-11 measurements was used (cf. infra). 


\section{CPT-11 measurements in tumour tissue and plasma}

A high-performance liquid chromatographic (HPLC) method was used and validated for the simultaneous determination of CPT-11, its metabolite $\mathrm{SN}-38$, and $\mathrm{H} 33342$, in human plasma and tumour tissue. Camptothecin (CPT) was used as an internal standard. As sample pretreatment, $10 \mu \mathrm{l}$ of HPLC grade methanol was added to $50 \mu \mathrm{l}$ plasma together with $100 \mu \mathrm{l}$ internal standard solution. After vortexing, the solution was heated to $40^{\circ} \mathrm{C}$ for $15 \mathrm{~min}$. An additional $200 \mu \mathrm{l}$ of triethylamine-acetate buffer was then added to the solution, which was centrifuged at 14000 r.p.m. for $5 \mathrm{~min}$. Finally, the supernatant was filtered over a $0.2 \mu \mathrm{m}$ PVDF HPLCfilter and $20 \mu \mathrm{l}$ was injected into the HPLC system. After mechanical mixing of tumour tissue to generate emulsions of cellular debris, a similar procedure was followed. Separation was achieved on a Waters Symmetry 300 C8 reversed-phase column $(25 \mathrm{~cm} \times 4.6,5 \mu \mathrm{m})$. The mobile phase consisted of $72 \%$ triethylamine-acetate buffer $(\mathrm{pH} 5.2)$ and $28 \%$ acetonitrile at a flow rate of $1.5 \mathrm{ml} \mathrm{min}^{-1}$. CPT-11 and CPT were detected by fluorescence with excitation and emission wavelengths of 369 and $424 \mathrm{~nm}$, respectively. SN-38 and $\mathrm{H} 33342$ were detected by fluorescence with respective excitation and emission wavelengths of 376 and $534 \mathrm{~nm}$. The limits of quantitation for CPT-11, SN-38, and H33342 were 0.5 , 0.25 and $0.5 \mathrm{ng} \mathrm{ml}^{-1}$, respectively. Within-run and between-run precisions were less than $10 \%$ and average accuracies were between 90 and $110 \%$.

\section{Statistical analysis}

'Statistica 5.5' was used for statistical analysis. Unless indicated, Student's $t$-test was used to evaluate differences between two independent groups, and data are presented as mean \pm s.d. The significance level was determined at 0.05 . The tumour growth delay calculations were based on the growth increase for a defined period, the tumour volume reached at a defined time point, and the time to grow from the starting volume to a higher defined volume. Since the time points of interest varied for the several questions posed, different parameters were used for the different groups.

\section{RESULTS}

\section{Anti-VEGF mAb does not impair intratumoral CPT-11 delivery}

Pretreatment with anti-VEGF mAb produces a trend to higher intratumoral availability of CPT-11; mean \pm s.d. 15.98 \pm $11.67 \mu \mathrm{g} \mathrm{g}^{-1}$ vs $10.93 \pm 5.39 \mu \mathrm{gg}^{-1}$ tumour tissue $(P=0.09)$ (Figure 1). There was no difference in the mean plasma CPT-11 level in the two groups; $21.31 \pm 8.03 \mu \mathrm{g} \mathrm{ml}^{-1}$ in the anti-VEGF mAb group and $19.37 \pm 10.14 \mu \mathrm{g} \mathrm{ml}^{-1}$ in the placebo group $(P=0.77)$. The intratumoral levels of the active metabolite SN-38 were about 50 times smaller, with no significant difference between the antiVEGF mAb group $\left(0.26 \pm 0.10 \mu \mathrm{gg}^{-1}\right)$ and the placebo group $\left(0.24 \pm 0.09 \mu \mathrm{g} \mathrm{g}^{-1}\right)(P=0.49)$. The mean tumour volume at day 7 , the time of excision, was significantly lower $(P<0.001)$ in the antiVEGF mAb-treated group $\left(355 \pm 123 \mathrm{~mm}^{3}\right)$ compared to the placebo group $\left(492 \pm 113 \mathrm{~mm}^{3}\right)$.

\section{Anti-VEGF mAb reduces tumour VD}

At 1 week after the first treatment with anti-VEGF mAb, total VD decreased significantly by $20.1 \%$ on CD34 slides and $26.4 \%$ on CD105 slides (Table 1). The large-vessel VD decreased by 53.4 and $52.1 \%$ on CD34 and CD105 slides, respectively. The vessel diameter of large vessels was decreased to a lesser but significant extent after anti-VEGF mAb, by 19.2 and $21.1 \%$, respectively. Total and endothelial cord VD were lower on CD105 than on CD34 slides. In

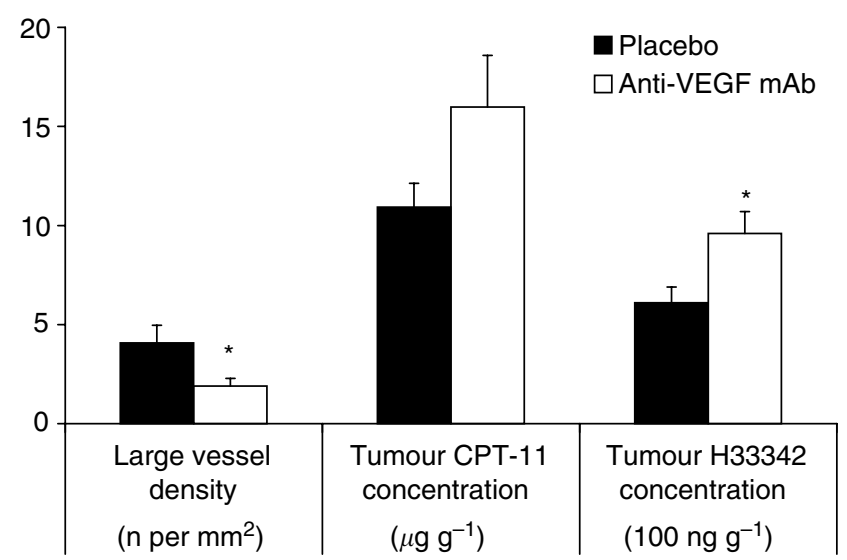

Figure I After anti-VEGF mAb therapy, large-vessel VD decreases $(P=0.03)$ while intratumoral $\mathrm{H} 33342$, injected I min before killing as indicator of tumour perfusion, increases $(P=0.0 \mathrm{I})$. There is a trend to higher intratumoral concentration of CPT-II in the anti-VEGF-mAbtreated group $(P=0.09)$. Asterisks, $P<0.05$ vs placebo. Data indicate mean \pm s.e.

contrast, large-vessel VD was more than twice as high after CD105 compared to CD34 staining, which was confirmed by the two independent observers. There was no difference in the estimated necrosis of tumours treated with anti-VEGF mAb $(37 \pm 17.6 \%)$ or placebo $(34.5 \pm 21.9 \%)(P=0.69)$. An example of histological sections of anti-VEGF mAb and placebo-treated tumours is shown (Figure 2).

\section{Tumour growth delay}

There was progressive growth of HT29 tumours up to volumes of $1000 \mathrm{~mm}^{3}$. Anti-VEGF mAb retarded growth significantly, with a mean tumour growth delay of 8 days. CPT- 11 as a single bolus $\mathrm{LD}_{0}$ dose, resulted in only a moderate growth delay of about $2-3$ days, which was not altered when CPT-11 was administered after pretreatment with anti-VEGF mAb (Figure 3; Table 2).

\section{Determination of vascular function using the perfusion marker H33342}

Five of the 40 tumour samples, were excluded due to analytical error. The intratumoral $\mathrm{H} 33342$ concentration was $57 \%$ higher in the anti-VEGF-mAb-treated group $(n=16)$ than in the placebo group $(n=19)(P=0.01)$ (Figure 1$)$.

\section{DISCUSSION}

\section{Anti-VEGF mAb does not impair intratumoral CPT-11 delivery}

For any cancer treatment to be successful, it needs to meet at least two major criteria. Firstly, it must be potent and effective in destroying or inhibiting cancer cells in vivo, and this must be achieved with acceptable toxicity to normal host tissues. Hence, it must be possible to deliver the drug in vivo into the tumour tissue in sufficiently high concentrations. Different barriers to successful drug delivery have been recognised, as highlighted by Jain (1994, 1997, 1998). The chaotic blood supply, the quality of the vessel wall, and the interstitium can all play a major role in preventing efficient drug delivery (Jain, 1987). Antiangiogenic therapy can interfere significantly with these three factors, but studies of the impact of AAT on the delivery of concomitant cytotoxic drugs are very sparse. 
Table I Effect of anti-VEGF mAb on tumor vessel density (VD)

\begin{tabular}{|c|c|c|c|c|}
\hline & Anti-VEGF $(n=20)$ & Placebo $(n=20)$ & $P$ & Difference (\%) \\
\hline \multicolumn{5}{|l|}{ CD34-stained sections } \\
\hline Total VD $\left(n\right.$ per $\left.\mathrm{mm}^{2}\right)$ & $36.5+3.3^{\mathrm{a}}$ & $45.7+2.4$ & $0.027 *$ & 20.1 \\
\hline Endothelial cords VD $\left(n\right.$ per $\left.\mathrm{mm}^{2}\right)$ & $34.6 \pm 3.2$ & $41.6 \pm 2.4$ & 0.08 & 16.8 \\
\hline Large vessel VD $\left(n \text { per } \mathrm{mm}^{2}\right)^{\mathrm{b}}$ & $1.90 \pm 0.38$ & $4.08 \pm 0.88$ & $0.029 *$ & 53.4 \\
\hline Vessel diameter $(\mu \mathrm{m})$ & $14.3 \pm 0.69$ & $17.7 \pm 0.56$ & $<0.001 *$ & 19.2 \\
\hline \multicolumn{5}{|l|}{ CDI05-stained sections } \\
\hline Total VD $\left(n\right.$ per $\left.\mathrm{mm}^{2}\right)$ & $29.0 \pm 2.4$ & $39.4 \pm 2.2$ & $0.0026 *$ & 26.4 \\
\hline Endothelial cords VD ( $n$ per $\left.\mathrm{mm}^{2}\right)$ & $24.9 \pm 2.4$ & $30.8 \pm 2.3$ & 0.078 & 19.1 \\
\hline Large vessel VD $\left(n\right.$ per $\left.\mathrm{mm}^{2}\right)$ & $4.12 \pm 0.58$ & $8.60 \pm 1.1$ & $0.001 *$ & 52.1 \\
\hline Vessel diameter $(\mu \mathrm{m})$ & $12.7 \pm 0.44$ & $16.1 \pm 0.37$ & $<0.001 *$ & 21.1 \\
\hline
\end{tabular}

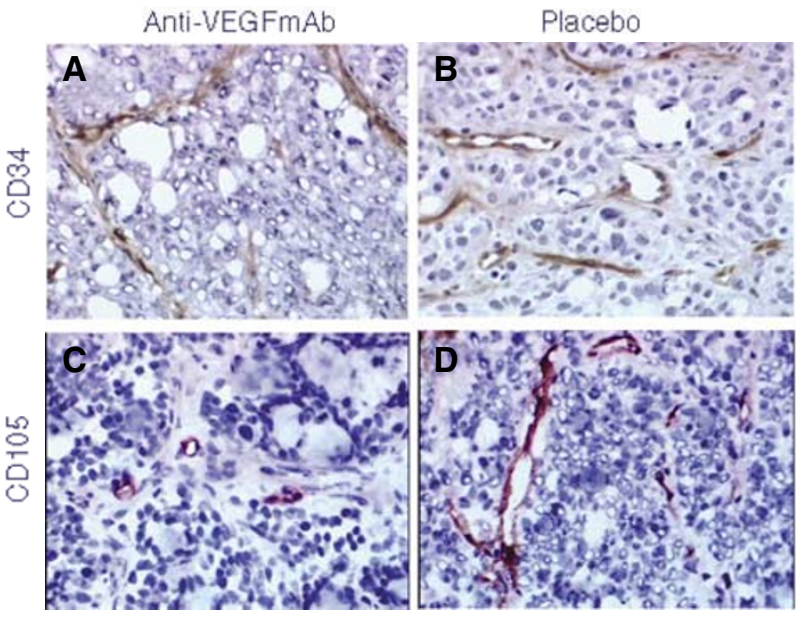

Figure 2 CD34 (A, B) and CDI05 (C, D) staining of colorectal tumours shows decreased VD in tumours treated with anti-VEGF $m A b$ $(\mathbf{A}, \mathbf{C})$ vs placebo $(\mathbf{B}, \mathbf{D})$. Original magnification $\times 200$.

Our investigation aimed to study this question, and to quantitatively evaluate the importance of the tumour perfusion as the first barrier. This in turn raised the question of whether VD per se could be a predictive tool for tumour uptake of cytotoxic drugs. Our results clearly show that anti-VEGF mAb definitely does not impair, and may even improve intratumoral uptake of CPT-11 in this tumour model. This is remarkable because antiVEGF mAb clearly decreases tumour VD in this model. These data are consistent with our previous work where we showed a lack of correlation between melphalan tumour uptake and VD (Wildiers et al, 2002). A plausible explanation might be that although fewer vessels are present, they are of better quality, likely allowing improved delivery of bloodborne agents. The counting of vessels does not seem to reflect their perfusion status. Many tumour vessels are only perfused temporarily (Chaplin and Hill, 1995), or sometimes not at all (Vajkoczy et al, 2000). In addition to vascular length, tissue perfusion is determined by mean vessel diameter, flow resistance, and erythrocyte velocity (Intaglietta and Zweifach, 1974; Leunig et al, 1992; Baish et al, 1996; Vajkoczy et al, 1998). We correlated our data with measurement of functional vasculature, indicating a $57 \%$ increase in intratumoral perfusion after antiVEGF mAb treatment, consistent with the trend of increased tumour CPT-11 uptake. Our data support the proposed concept of 'normalising' tumour vasculature with AAT (Jain, 2001). Pruning of immature and inefficient blood vessels by eliminating excess endothelial cells could result in a more 'normal' vasculature, which
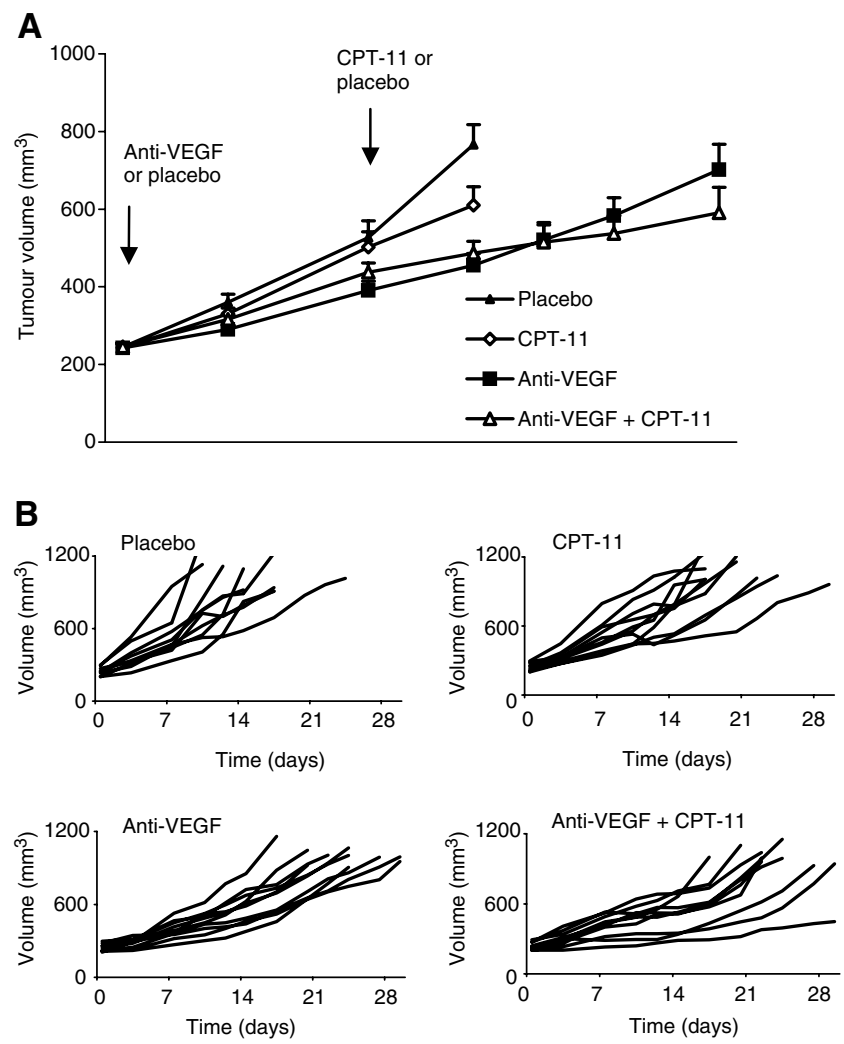

Figure 3 Effect of anti-VEGF $m A b, C P T-I I$, and the combination of antiVEGF $m A b$ and CPT-I I on the growth of HT29 colonic tumours in mice ( $n=10$ per group). (A) Mean tumour growth. The growth curve of each subgroup was terminated when one mouse in that subgroup developed a tumour of $1000 \mathrm{~mm}^{3}$, to avoid nonrepresentative mean growth curves. Data points indicate the mean \pm s.e. (B) The individual growth curves of different subgroups.

is better equipped to deliver nutrients and therapeutic agents. It seems plausible that the above-mentioned phenomenon is an important mechanism for the observed increased CPT-11 uptake, but other known and unknown mechanisms might be involved and are discussed below.

Apart from tumour perfusion (the 'first' barrier), also vascular permeability (the 'second' barrier) could theoretically play a role in the delivery of anticancer agents. In general, the microvasculature of solid tumours is hyperpermeable to macromolecules in comparison to normal vessels. This is presumably due to 
Table 2 Effect of CPT-II and anti-VEGFmAb on tumour growth parameters

\begin{tabular}{|c|c|c|c|}
\hline Effect of anti-VEGFmAb on tumour growth & Anti-VEGF & Placebo & $\boldsymbol{P}$ \\
\hline Start volume at day 0 (start of anti-VEGFmAb or placebo) & $242 \pm 9.8^{\mathrm{a}}$ & $244 \pm 11.2$ & \\
\hline Growth increase from day 0 to day 10 (multiplication factor) & $1.91 \pm 0.13$ & $3.08 \pm 0.26$ & $0.0009 *$ \\
\hline Tumour volume at day $10\left(\mathrm{~mm}^{3}\right)$ & $458 \pm 29$ & $766 \pm 91$ & $0.005 *$ \\
\hline Time to grow from 250 to $900 \mathrm{~mm}^{3}$ (days) & $21.5 \pm 1.37$ & $13.6 \pm 1.65$ & $0.00007 *$ \\
\hline Effect of CPT-I I on tumour growth & CPT-I I & Placebo & $\boldsymbol{P}$ \\
\hline Start volume at day 7 (start of CPT-I I or placebo) & $502 \pm 70$ & $527 \pm 54$ & \\
\hline Growth increase from day 7 to day 10 (multiplication factor) & $1.21 \pm 0.03$ & $1.46 \pm 0.10$ & $0.04 *$ \\
\hline Tumour volume at day $14\left(\mathrm{~mm}^{3}\right)^{\mathrm{b}}$ & $660 \pm 55$ & $840 \pm 59$ & $0.04 *$ \\
\hline Time to grow from volume 500 to $900 \mathrm{~mm}^{3}$ (days) & $8.73 \pm 1.28$ & $6.61 \pm 1.04$ & 0.12 \\
\hline Effect of CPT-I I after anti-VEGFmAb on tumour growth & Anti-VEGF+CPT-I I & Anti-VEGF & $\boldsymbol{P}$ \\
\hline Start volume at day 7 (start of CPT-II or placebo) & $407 \pm 30$ & $391 \pm 24$ & \\
\hline Growth increase from day 7 to day 17 (multiplication factor) & $1.46 \pm 0.10$ & $1.78 \pm 0.08$ & $0.02 *$ \\
\hline Tumour volume at day $17\left(\mathrm{~mm}^{3}\right)$ & $599 \pm 61$ & $702 \pm 65$ & 0.27 \\
\hline Time to grow from volume 400 to $700 \mathrm{~mm}^{3}$ (days) & $11.35 \pm 2.9$ & $8.76 \pm 2.28$ & $0.04 *$ \\
\hline
\end{tabular}

a Mean \pm s.e. ${ }^{b} n=7$ in both groups. $*$ Significant at level $<0.05$.

interactions between vascular endothelial cells and VEGF, also known as the vascular permeability factor (VPF). It has been demonstrated that tumour vascular permeability can be reduced by neutralization of endogenous VEGF with the anti-VEGF mAb A4.6.1 (Yuan et al, 1996). Although VEGF increases vascular permeability, our data do not suggest that blocking VEGF decreases permeability to CPT-11, as delivery was improved rather than diminished. Vascular permeability is probably more important for large molecules (Teicher et al, 1995b), and less so for small molecules (Wildiers et al, 2002) such as CPT-11 and SN-38, which have molecular weights of 586 and $392 \mathrm{~g} \mathrm{~mol}^{-1}$, respectively. In short, changes in vessel permeability do not seem to play a major role in the observed increased uptake of CPT- 11 .

Also interstitial transport (the 'third' barrier) could play a role in the intratumoral availability of small drugs such as CPT-11. The uniformly elevated interstitial fluid pressure in solid tumours leads to negligible convection in the tumour interstitium (Boucher et al, 1990), and drug delivery through the extracellular matrix (ECM) relies on passive diffusive transport (Netti et al, 1999). This transport is influenced by the constituents and characteristics of the ECM (Pluen et al, 2001). Interstitial pressure decreases by $74 \%$ in the LS174T colorectal cancer tumour model after pretreatment with A4.6.1 (Lee et al, 2000). It is therefore also possible that decreased interstitial fluid pressure allows convection again to a certain degree, leading to better delivery despite a decreased number of vessels.

Since necrosis can be expected to influence the intratumoral uptake of drugs such as CPT-11, we estimated the amount of necrosis in each tumour. Anti-VEGF mAb does not influence the amount of necrosis in this tumour type, and this aspect can therefore not explain the differences in the results we obtained on intratumoral availability of CPT- 11 .

Since intratumoral $\mathrm{pH}$ seems an important but relatively little studied parameter influencing drug uptake and resistance (Simon, 1999), $\mathrm{pH}$ alterations after anti-VEGF mAb could have influenced CPT-11 and SN-38 uptake. CPT-11 has a very complex pharmacology, and is known in two forms, an active lactone form and an inactive carboxylate form, between which a pH-dependent equilibrium exists that significantly impacts on the kinetic profile of the compound (Gelderblom et al, 1999; Mathijssen et al, 2001). The uptake of CPT-11 and SN-38 by intestinal cells has been demontrated to be clearly $\mathrm{pH}$ sensitive. At physiological $\mathrm{pH}$, the uptake rates of CPT-11 and SN-38 decreased significantly by $65 \%$ at $\mathrm{pH}$ greater than 6.8, and accordingly, uptake rates of both lactones were significantly higher than those of their carboxylates (Kobayashi et al, 1999). Moreover, a decreased uptake of SN-38 with increasing $\mathrm{pH}$ correlated with a smaller cytotoxic effect. To our knowledge, the effect of anti-VEGF therapy on tumour $\mathrm{pH}$ and its correlation with uptake of anticancer drugs has not been consistently studied, and is a very interesting domain for further research.

The trend in increased intratumoral availability was only identified with the abundant parent compound CPT-11, and not for SN-38. There is no clear explanation for this at the moment; however, some remarks can be considered. Intratumoral SN-38 was only measurable at concentrations 50 times lower than CPT11. It is known that only a limited amount of CPT-11 is transformed into SN-38 (Chabot, 1997), which agrees with plasma levels being about 12 times lower than CPT-11 in our study (data not shown). Intratumoral SN-38 levels were somewhat higher after anti-VEGF therapy, but not significantly. These results are thus not really contradictory with the CPT-11 findings.

The measurements of CPT-11 only represent concentrations in the whole tumour, not only tumour cells, but also blood vessels and the interstitium. It was not possible to distinguish differences in CPT-11 concentrations within the different compartments in the present study. Plasma and red blood cells in the tumoral vessels also contain CPT-11 (Combes et al, 2000), and it is therefore possible that differences in intratumoral blood volume, secondary to AAT, may be a factor. However, blood vessels comprise only about $7 \%$ of the total tumour volume in this model (from a random sample of four tumours, data not shown), and about $91 \%$ of the vessels counted were endothelial cords without a lumen (Table 1). Assuming the volume of blood in the tumour is $5 \%$ (probably an overestimate), then $20 \mu \mathrm{l}$ will be present in a tumour of $400 \mathrm{~mm}^{3}(400 \mu \mathrm{l})$. With a plasma concentration of $20 \mu \mathrm{g} \mathrm{ml}^{-1}$ and with approximately $40 \%$ of CPT-11 present in erythrocytes, tumoral blood only contains $0.4 \mu \mathrm{g}$ of a total tumour concentration of $4 \mu \mathrm{g}$. Therefore, at most $10 \%$ of the intratumoral CPT- 11 is derived from blood, and this amount will not greatly affect the measurements.

\section{Anti-VEGF mAb reduces tumour VD}

As anti-VEGF mAb inhibits the formation of new blood vessels, it is logical that tumour VD decreases. However, most investigators have looked at total $\mathrm{VD}$, which in some tumour types is predominantly determined by endothelial cords that presumably 
play only a minor role in the delivery and transport of nutrients and drugs, as there is no lumen present. We have found that VEGF $\mathrm{mAb}$ diminishes more the number of larger vessels than of endothelial cords in this HT29 human xenograft colorectal tumour model. This effect could be due to inhibition of larger vessel formation, or to a decrease in size of existing larger vessels. In the setting of drug delivery, and in view of transport capacity, it is important to assess the role of large vessels specifically.

To evaluate vasculature on tumour sections, various antibodies to endothelial cells (EC) are available. CD34 is one of the classical targets to identify EC, and has been called a 'panendothelial' marker. CD105 or endoglin is a more recently recognised endothelial antigen that is strongly expressed on proliferating EC, but little or not on resting EC. Therefore, CD105 represents a powerful marker of neovascularisation (Fonsatti et al, 2000, 2001). Blood vessel counts using CD105 are a better prognostic factor than CD34 in patients with breast cancer (Kumar et al, 1999). The vessel counts of endothelial cords, representing the majority of vessels counted, are lower with CD105 than with CD34 staining. In contrast, large-vessel VD, which reflects potentially perfused vessels, was more than twice as high with CD105 than with CD34 staining. It is known that CD34 expression on endothelial cells can be downregulated during proliferation, and endothelial cells of larger veins have been reported to be CD34 negative (Delia et al, 1993; Muller et al, 2002). Our data confirm these observations, and suggest that CD105 staining is necessary to assess large vessels.

\section{Tumour growth delay}

The enhanced antitumour effect of chemotherapeutic agents when combined with AAT (Teicher et al, 1992, 1994; Sweeney et al, 2001) is probably not only due to differences in vascularisation, perfusion and drug delivery, but also an increase in tumour cell apoptosis (Kamiya et al, 1999; Wassberg et al, 1999). VEGF is a recognised chemoprotectant, particularly for drugs that inhibit microtubules, by reducing the proapoptotic effect of chemotherapy (Tran et al, 2002). Inhibiting proangiogenic factors such as VEGF with AAT may make endothelial cells more sensitive to cytotoxic agents.

The tumour growth delay with anti-VEGF mAb confirms previous observations in colon cancer and other tumour models (Lee et al, 2000). It must be emphasised that anti-VEGF mAb was administered only twice for the specific purpose of this study, and prolonged administration would probably result in longer growth delays. Similarly, CPT-11 was administered only as a single $\mathrm{LD}_{0}$ bolus. Higher response rates and increased tumour growth inhibition have been reported with fractionated regimens in mice, for example, every 4 days for 3 cycles (Lavelle et al, 1996), 6-day courses (O'Leary et al, 1999), or at low doses $\left(10 \mathrm{mg} \mathrm{kg}^{-1}\right)$ in protracted schedules of several weeks (Houghton et al, 1995), administering a higher total dose. Regardless, CPT-11 retards tumour growth with or without anti-VEGF mAb pretreatment, and our data certainly do not show antagonism between CPT-11 and anti-VEGF mAb. The anti-VEGF mAb + CPT-11 group grew faster from day 0 to day 7 , in comparison with the anti-VEGF mAb alone group (Figure 3 ), but not significantly $(P=0.68)$. Nevertheless, following CPT-11 administration to the former group at day 7 , the growth curves clearly cross, indicating effective growth inhibition in this subgroup.

\section{REFERENCES}

Baish JW, Gazit Y, Berk DA, Nozue M, Baxter LT, Jain RK (1996) Role of tumor vascular architecture in nutrient and drug delivery:
It is also interesting that a clear antiangiogenic effect of CPT-11, separate from the antitumour cell effect, has been reported (O'Leary et al, 1999). The study period allowing only $1 \mathrm{~h}$ exposure to CPT-11 was too short to evaluate this effect.

It is remarkable that the anti-VEGF mAb A4.6.1 substantially reduces, but does not completely suppress, tumour growth after systemic administration. The main mechanism of action is probably blockade of human VEGF (VEGF 165) in the xenograft tumours. However, it has been shown that host VEGF (VEGF 164 in mice) can also significantly contribute to tumour growth (Gerber et al, 2000). For maximum inhibition of tumour growth in human xenograft tumour models in mice, it is probably necessary to block VEGF completely.

\section{Determination of vascular function using the perfusion marker H33342}

H33342 is used as an index of functional vascular volume, and quantified with a random sampling procedure using the Chalkley method on histological slides (Smith et al, 1988; Quinn et al, 1992). However, the detection of all the $\mathrm{H} 33342$ in the tumour may be a more global index of whole tumour perfusion. Using the same HPLC conditions as for CPT-11 and SN-38, we were able to detect and quantify $\mathrm{H} 33342$ as a distinct peak on the chromatogram. This concentration reflects the global uptake of H33342, but can be altered by many physiological parameters including blood flow, permeability, blood pressure, and interstitial pressure. It is a recognised relative rather than an absolute index of perfusion and functional vasculature, allowing comparison between different treatments in tumour models. This approach is original, objective, and feasible when HPLC technology is available. H33342 is vasoactive at doses above $10 \mathrm{mg} \mathrm{kg}^{-1}$ (Trotter et al, 1990). However, the validity of the data is not affected, as such an effect would only be expected to influence absolute, but not relative, uptake. The uptake in treated tumours was compared to that of controls.

In summary, our results show that the anti-VEGF mAb tends to improve CPT-11 delivery, and this corresponds to an increase in tumour perfusion, even though VD is significantly decreased. This increased perfusion is a plausible cause of the observed increase in CPT-11 uptake, although other phenomena might be involved. Interestingly, the tumour growth delay induced by the combination of anti-VEGF mAb and CPT-11 is at least additive. Tumour VD lacks predictive power for intratumoral delivery of anticancer drugs. Immunohistological staining of endothelial cells with CD34 and CD105, and the separation of endothelial cord and large vessel densities, provide additional information on tumour vascularisation. A new index of functional vasculature and perfusion using HPLC determination of intratumoral H33342 is described, allowing comparison of different treatments in tumour models.

\section{ACKNOWLEDGEMENTS}

This work was supported by a fellowship from the 'Fonds voor Wetenschappelijk Onderzoek-Vlaanderen' (HW) and a fellowship from 'Vlaams Instituut voor de Bevordering van het Wetenschappelijk-technologisch Onderzoek in de Industrie' (BL). We sincerely thank Ulla Vanleeuw and Kathleen Corthouts for their outstanding technical assistance, and Martin Highley for the fruitful discussion on the text. an invasion percolation-based network model. Microvasc Res 51: $327-346$ 
Beecken WD, Fernandez A, Joussen AM, Achilles EG, Flynn E, Lo KM, Gillies SD, Javaherian K, Folkman J, Shing Y (2001) Effect of antiangiogenic therapy on slowly growing, poorly vascularized tumors in mice. J Natl Cancer Inst 93: 382-387

Bernsen HJ, Rijken PF, Hagemeier NE, van der Kogel AJ (1999) A quantitative analysis of vascularization and perfusion of human glioma xenografts at different implantation sites. Microvasc Res 57: 244-257

Bhargava P, Marshall JL, Rizvi N, Dahut W, Yoe J, Figuera M, Phipps K, Ong VS, Kato A, Hawkins MJ (1999) A Phase I and pharmacokinetic study of TNP-470 administered weekly to patients with advanced cancer. Clin Cancer Res 5: 1989-1995

Borgstrom P, Bourdon MA, Hillan KJ, Sriramarao P, Ferrara N (1998) Neutralizing anti-vascular endothelial growth factor antibody completely inhibits angiogenesis and growth of human prostate carcinoma micro tumors in vivo. Prostate 35: $1-10$

Boucher Y, Baxter LT, Jain RK (1990) Interstitial pressure gradients in tissue-isolated and subcutaneous tumors: implications for therapy. Cancer Res 50: $4478-4484$

Browder T, Butterfield CE, Kraling BM, Shi B, Marshall B, O'Reilly MS, Folkman J (2000) Antiangiogenic scheduling of chemotherapy improves efficacy against experimental drug-resistant cancer. Cancer Res 60: $1878-1886$

Bussink J, Kaanders JH, Rijken PF, Raleigh JA, van der Kogel AJ (2000) Changes in blood perfusion and hypoxia after irradiation of a human squamous cell carcinoma xenograft tumor line. Radiat Res 153: $398-404$

Chabot GG (1997) Clinical pharmacokinetics of irinotecan. Clin Pharmacokinet 33: 245-259

Chaplin DJ, Hill SA (1995) Temporal heterogeneity in microregional erythrocyte flux in experimental solid tumours. Br J Cancer 71: $1210-$ 1213

Combes O, Barre J, Duche JC, Vernillet L, Archimbaud Y, Marietta MP, Tillement JP, Urien S (2000) In vitro binding and partitioning of irinotecan (CPT-11) and its metabolite, SN-38, in human blood. Invest New Drugs 18: $1-5$

Delia D, Lampugnani MG, Resnati M, Dejana E, Aiello A, Fontanella E, Soligo D, Pierotti MA, Greaves MF (1993) CD34 expression is regulated reciprocally with adhesion molecules in vascular endothelial cells in vitro. Blood 81: $1001-1008$

Fonsatti E, Del Vecchio L, Altomonte M, Sigalotti L, Nicotra MR, Coral S, Natali PG, Maio M (2001) Endoglin: an accessory component of the TGF-beta-binding receptor-complex with diagnostic, prognostic, and bioimmunotherapeutic potential in human malignancies. J Cell Physiol 188: $1-7$

Fonsatti E, Jekunen AP, Kairemo KJ, Coral S, Snellman M, Nicotra MR, Natali PG, Altomonte M, Maio M (2000) Endoglin is a suitable target for efficient imaging of solid tumors: in vivo evidence in a canine mammary carcinoma model. Clin Cancer Res 6: 2037-2043

Gee MS, Saunders HM, Lee JC, Sanzo JF, Jenkins WT, Evans SM, Trinchieri G, Sehgal CM, Feldman MD, Lee WM (2001) Doppler ultrasound imaging detects changes in tumor perfusion during antivascular therapy associated with vascular anatomic alterations. Cancer Res 61: 2974-2982

Gelderblom HA, DE Jonge MJ, Sparreboom A, Verweij J (1999) Oral topoisomerase 1 inhibitors in adult patients: present and future. Invest New Drugs 17: $401-415$

Gerber HP, Kowalski J, Sherman D, Eberhard DA, Ferrara N (2000) Complete inhibition of rhabdomyosarcoma xenograft growth and neovascularization requires blockade of both tumor and host vascular endothelial growth factor. Cancer Res 60: 6253-6258

Goertz DE, Yu JL, Kerbel RS, Burns PN, Foster FS (2002) High-frequency Doppler ultrasound monitors the effects of antivascular therapy on tumor blood flow. Cancer Res 62: 6371-6375

Gorski DH, Beckett MA, Jaskowiak NT, Calvin DP, Mauceri HJ, Salloum RM, Seetharam S, Koons A, Hari DM, Kufe DW, Weichselbaum RR (1999) Blockage of the vascular endothelial growth factor stress response increases the antitumor effects of ionizing radiation. Cancer Res 59: $3374-3378$

Gundersen HJ (1978) Estimators of the number of objects per area unbiased by edge effects. Microsc Acta 81: 107-117

Houghton PJ, Cheshire PJ, Hallman JD, Lutz L, Friedman HS, Danks MK, Houghton JA (1995) Efficacy of topoisomerase I inhibitors, topotecan and irinotecan, administered at low dose levels in protracted schedules to mice bearing xenografts of human tumors. Cancer Chemother Pharmacol 36: $393-403$
Ingber D, Fujita T, Kishimoto S, Sudo K, Kanamaru T, Brem H, Folkman J (1990) Synthetic analogues of fumagillin that inhibit angiogenesis and suppress tumour growth. Nature 348: 555-557

Intaglietta M, Zweifach BW (1974) Microcirculatory basis of fluid exchange. Adv Biol Med Phys 15: $111-159$

Jain RK (1987) Transport of molecules in the tumor interstitium: a review. Cancer Res 47: 3039-3051

Jain RK (1994) Barriers to drug delivery in solid tumors. Sci Am 271: 58 - 65

Jain RK (1997) The Eugene M. Landis Award Lecture 1996. Delivery of molecular and cellular medicine to solid tumors. Microcirculation 4: $1-23$

Jain RK (1998) The next frontier of molecular medicine: delivery of therapeutics. Nat Med 4: 655-657

Jain RK (2001) Normalizing tumor vasculature with anti-angiogenic therapy: a new paradigm for combination therapy. Nat Med 7: 987-989

Kamiya K, Konno H, Tanaka T, Baba M, Matsumoto K, Sakaguchi T, Yukita A, Asano M, Suzuki H, Arai T, Nakamura S (1999) Antitumor effect on human gastric cancer and induction of apoptosis by vascular endothelial growth factor neutralizing antibody. Jpn J Cancer Res 90: 794-800

Kaneda N, Nagata H, Furuta T, Yokokura T (1990) Metabolism and pharmacokinetics of the camptothecin analogue CPT-11 in the mouse. Cancer Res 50: $1715-1720$

Kim KJ, Li B, Winer J, Armanini M, Gillett N, Phillips HS, Ferrara N (1993) Inhibition of vascular endothelial growth factor-induced angiogenesis suppresses tumour growth in vivo. Nature 362: $841-844$

Klement G, Baruchel S, Rak J, Man S, Clark K, Hicklin DJ, Bohlen P, Kerbel RS (2000) Continuous low-dose therapy with vinblastine and VEGF receptor-2 antibody induces sustained tumor regression without overt toxicity. J Clin Invest 105: R15- R24

Kobayashi K, Bouscarel B, Matsuzaki Y, Ceryak S, Kudoh S, Fromm H (1999) $\mathrm{pH}$-dependent uptake of irinotecan and its active metabolite, SN38, by intestinal cells. Int J Cancer 83: 491-496

Kozin SV, Boucher Y, Hicklin DJ, Bohlen P, Jain RK, Suit HD (2001) Vascular endothelial growth factor receptor-2-blocking antibody potentiates radiation-induced long-term control of human tumor xenografts. Cancer Res 61: 39-44

Kumar S, Ghellal A, Li C, Byrne G, Haboubi N, Wang JM, Bundred N (1999) Breast carcinoma: vascular density determined using CD105 antibody correlates with tumor prognosis. Cancer Res 59: 856-861

Lavelle F, Bissery MC, Andre S, Roquet F, Riou JF (1996) Preclinical evaluation of CPT-11 and its active metabolite SN-38. Semin Oncol 23: $11-20$

Lee CG, Heijn M, di Tomaso E, Griffon-Etienne G, Ancukiewicz M, Koike C, Park KR, Ferrara N, Jain RK, Suit HD, Boucher Y (2000) AntiVascular endothelial growth factor treatment augments tumor radiation response under normoxic or hypoxic conditions. Cancer Res 60: $5565-5570$

Leunig M, Yuan F, Menger MD, Boucher Y, Goetz AE, Messmer K, Jain RK (1992) Angiogenesis, microvascular architecture, microhemodynamics, and interstitial fluid pressure during early growth of human adenocarcinoma LS174T in SCID mice. Cancer Res 52: 6553-6560

Ljungkvist AS, Bussink J, Rijken PF, Kaanders JH, van der Kogel AJ, Denekamp J (2002) Vascular architecture, hypoxia, and proliferation in first-generation xenografts of human head-and-neck squamous cell carcinomas. Int J Radiat Oncol Biol Phys 54: 215-228

Logothetis CJ, Wu KK, Finn LD, Daliani D, Figg W, Ghaddar H, Gutterman JU (2001) Phase I trial of the angiogenesis inhibitor TNP-470 for progressive androgen-independent prostate cancer. Clin Cancer Res 7: $1198-1203$

Man S, Bocci G, Francia G, Green SK, Jothy S, Hanahan D, Bohlen P, Hicklin DJ, Bergers G, Kerbel RS (2002) Antitumor effects in mice of lowdose (metronomic) cyclophosphamide administered continuously through the drinking water. Cancer Res 62: 2731-2735

Mathijssen RH, van Alphen RJ, Verweij J, Loos WJ, Nooter K, Stoter G, Sparreboom A (2001) Clinical pharmacokinetics and metabolism of irinotecan (CPT-11). Clin Cancer Res 7: 2182-2194

Muller AM, Hermanns MI, Skrzynski C, Nesslinger M, Muller KM, Kirkpatrick CJ (2002) Expression of the endothelial markers PECAM-1, vWf, and CD34 in vivo and in vitro. Exp Mol Pathol 72: 221-229

Netti PA, Hamberg LM, Babich JW, Kierstead D, Graham W, Hunter GJ, Wolf GL, Fischman A, Boucher Y, Jain RK (1999) Enhancement of fluid filtration across tumor vessels: implication for delivery of macromolecules. Proc Natl Acad Sci USA 96: 3137-3142

O’Leary JJ, Shapiro RL, Ren CJ, Chuang N, Cohen HW, Potmesil M (1999) Antiangiogenic effects of camptothecin analogues 9-amino-20(S)-camp- 
tothecin, topotecan, and CPT-11 studied in the mouse comea model. Clin Cancer Res 5: $181-187$

Pluen A, Boucher Y, Ramanujan S, McKee TD, Gohongi T, di Tomaso E, Brown EB, Izumi Y, Campbell RB, Berk DA, Jain RK (2001) Role of tumor-host interactions in interstitial diffusion of macromolecules: cranial vs subcutaneous tumors. Proc Natl Acad Sci USA 98: $4628-4633$

Quinn PK, Bibby MC, Cox JA, Crawford SM (1992) The influence of hydralazine on the vasculature, blood perfusion and chemosensitivity of MAC tumours. Br J Cancer 66: 323-330

Rowe DH, Huang J, Kayton ML, Thompson R, Troxel A, O'Toole KM, Yamashiro D, Stolar CJ, Kandel JJ (2000) Anti-VEGF antibody suppresses primary tumor growth and metastasis in an experimental model of Wilms' tumor. J Pediatr Surg 35: $30-32$

Shaheen RM, Tseng WW, Vellagas R, Liu W, Ahmad SA, Jung YD, Reinmuth N, Drazan KE, Bucana CD, Hicklin DJ, Ellis LM (2001) Effects of an antibody to vascular endothelial growth factor receptor-2 on survival, tumor vascularity, and apoptosis in a murine model of colon carcinomatosis. Int J Oncol 18: $221-226$

Simon SM (1999) Role of organelle $\mathrm{pH}$ in tumor cell biology and drug resistance. Drug Discov Today 4: 32-38

Smith KA, Hill SA, Begg AC, Denekamp J (1988) Validation of the fluorescent dye Hoechst 33342 as a vascular space marker in tumours. $\mathrm{Br}$ J Cancer 57: 247-253

Soh EY, Eigelberger MS, Kim KJ, Wong MG, Young DM, Clark OH, Duh QY (2000) Neutralizing vascular endothelial growth factor activity inhibits thyroid cancer growth in vivo. Surgery 128: $1059-1065$

Stadler WM, Kuzel T, Shapiro C, Sosman J, Clark J, Vogelzang NJ (1999) Multi-institutional study of the angiogenesis inhibitor TNP-470 in metastatic renal carcinoma. J Clin Oncol 17: 2541-2545

Sweeney CJ, Miller KD, Sissons SE, Nozaki S, Heilman DK, Shen J, Sledge Jr GW (2001) The antiangiogenic property of docetaxel is synergistic with a recombinant humanized monoclonal antibody against vascular endothelial growth factor or 2-methoxyestradiol but antagonized by endothelial growth factors. Cancer Res 61: $3369-3372$

Teicher BA, Dupuis NP, Robinson MF, Emi Y, Goff DA (1995a) Antiangiogenic treatment (TNP-470/minocycline) increases tissue levels of anticancer drugs in mice bearing Lewis lung carcinoma. Oncol Res 7: $237-243$

Teicher BA, Holden SA, Ara G, Dupuis NP, Liu F, Yuan J, Ikebe M, Kakeji Y (1995b) Influence of an anti-angiogenic treatment on 9L gliosarcoma: oxygenation and response to cytotoxic therapy. Int $J$ Cancer 61: $732-737$

Teicher BA, Holden SA, Ara G, Sotomayor EA, Huang ZD, Chen YN, Brem $\mathrm{H}$ (1994) Potentiation of cytotoxic cancer therapies by TNP-470 alone and with other anti-angiogenic agents. Int J Cancer 57: 920-925
Teicher BA, Sotomayor EA, Huang ZD (1992) Antiangiogenic agents potentiate cytotoxic cancer therapies against primary and metastatic disease. Cancer Res 52: 6702-6704

Teicher BA, Williams JI, Takeuchi H, Ara G, Herbst RS, Buxton D (1998) Potential of the aminosterol, squalamine in combination therapy in the rat 13,762 mammary carcinoma and the murine Lewis lung carcinoma. Anticancer Res 18: 2567-2573

Thomas CD, Stern S, Chaplin DJ, Guichard M (1996) Transient perfusion and radiosensitizing effect after nicotinamide, carbogen, and perflubron emulsion administration. Radiother Oncol 39: 235-241

Tomayko MM, Reynolds CP (1989) Determination of subcutaneous tumor size in athymic (nude) mice. Cancer Chemother Pharmacol 24: 148-154

Tran J, Master Z, Yu JL, Rak J, Dumont DJ, Kerbel RS (2002) A role for survivin in chemoresistance of endothelial cells mediated by VEGF. Proc Natl Acad Sci USA 99: 4349-4354

Trotter MJ, Olive PL, Chaplin DJ (1990) Effect of vascular marker Hoechst 33342 on tumour perfusion and cardiovascular function in the mouse. $\mathrm{Br}$ J Cancer 62: $903-908$

United Kingdom Co-ordinating Committee on Cancer Research (UKCCCR) (1998) Guidelines for the Welfare of Animals in Experimental Neoplasia (Second Edition). Br J Cancer 77: 1-10

Vajkoczy P, Schilling L, Ullrich A, Schmiedek P, Menger MD (1998) Characterization of angiogenesis and microcirculation of high-grade glioma: an intravital multifluorescence microscopic approach in the athymic nude mouse. J Cereb Blood Flow Metab 18: 510-520

Vajkoczy P, Ullrich A, Menger MD (2000) Intravital fluorescence videomicroscopy to study tumor angiogenesis and microcirculation. Neoplasia 2: $53-61$

Wassberg E, Hedborg F, Skoldenberg E, Stridsberg M, Christofferson R (1999) Inhibition of angiogenesis induces chromaffin differentiation and apoptosis in neuroblastoma. Am J Pathol 154: 395-403

Wildiers H, Guetens G, de Boeck G, Landuyt W, Verbeken E, Highley M, de Bruijn EA, van Oosterom AT (2002) Melphalan availability in hypoxiainducible factor-1alpha $+/+$ and factor-1alpha $-/-$ tumors is independent of tumor vessel density and correlates with melphalan erythrocyte transport. Int J Cancer 99: 514-519

Yang JC, Haworth L, Steinberg SM, Rosenberg SA, Novotny W (2002) A randomized double-blind placebo controlled trial of bevacizumab (antiVEGF antibody) demonstrating a prolongation in time to progreesion in patients with metastatic renal cancer. Proc Am Soc Clin Oncol 2002, Abstract No 15

Yuan F, Chen Y, Dellian M, Safabakhsh N, Ferrara N, Jain RK (1996) Timedependent vascular regression and permeability changes in established human tumor xenografts induced by an anti-vascular endothelial growth factor/vascular permeability factor antibody. Proc Natl Acad Sci USA 93: $14765-14770$ 